\title{
Seeing is believing: the impact of body-worn cameras on court outcomes, a cluster-randomized controlled trial in Miami Beach
}

\author{
Kevin Petersen ${ }^{1}$ - Alejandro Mouro ${ }^{2}$ - Donald Papy ${ }^{3}$ - Noel Castillo ${ }^{2}$. \\ Barak Ariel $^{4,5}$
}

Accepted: 30 June 2021 / Published online: 21 September 2021

(C) The Author(s) 2021

\begin{abstract}
Objectives To assess the effects of BWCs on prosecutorial and court-related charge outcomes across multiple crime types, including domestic violence charges, crimes committed against police officers, and drug/alcohol charges.

Methods A cluster-randomized controlled trial with 22 spatiotemporal police units assigned to BWCs and 17 assigned to control conditions. Data from the State Attorney's Office were used to track convictions, adjudication withheld dispositions, and declined prosecutions for both experimental and control charges. A series of multilevel logistic and negative binomial regression models were used to estimate the effect of BWC footage on charge outcomes. Outcomes BWCs led to a significantly higher proportion of crimes against police officers resulting in convictions or adjudication withheld outcomes, and a significantly higher proportion of domestic violence charges resulting in convictions alone, compared to control charges. However, after the clustering effect was taken into account, only the effect of BWCs on crimes against police officers remained statistically significant.

Conclusion These early results suggest that BWCs have significant evidentiary value that varies by crime type. BWCs may be best suited to capture evidence

Barak Ariel

ba285@cam.ac.uk

Kevin Petersen

kpeter4@gmu.edu

1 Department of Criminology, Law and Society, George Mason University, Fairfax, VA 22030, USA

2 Miami Beach Police Department, Miami, FL 33139, USA

3 Miami Beach, Florida, USA

4 Institute of Criminology, University of Cambridge, Cambridge CB3 9DA, UK

5 Institute of Criminology, Faculty of Law, The Hebrew University of Jerusalem, Mt Scopus, Jerusalem, Israel
\end{abstract}


of crimes committed against police officers and potentially in domestic violence offenses as well.

Keywords Body-worn camera Police Prosecution $\cdot$ Adjudication withheld $\cdot$ Conviction · Criminal justice

\section{Introduction}

Largely prompted by highly publicized police shootings in the USA, body-worn cameras (BWC) have become one of "the most rapidly diffusing and costly technologies recently adopted by policing agencies" (Lum et al., 2020, p. 3). Law enforcement agencies around the globe have increasingly turned to BWCs to increase perceptions of accountability and transparency (Coudert et al., 2015; Hyland, 2018; Taylor, 2016), and billions of dollars in revenue have been, and continue to be, spent on BWC implementation (Friedman, 2015; Goodison et al., 2018). In response, research on the effects of BWCs has increased significantly in recent years. However, such research has primarily concentrated on a small set of outcomes, with particular focus on the effect of BWCs on use-of-force incidents and citizen complaints (see Ariel et al., 2015; Ariel et al., 2017; Jennings et al., 2015; Lum et al., 2019; Lum et al., 2020; Maskaly et al., 2017; White \& Malm, 2020).

As researchers continue to focus on the impacts of BWCs on police-citizen encounters, decidedly less attention has been given to the evidentiary value of BWC footage (see Lum et al., 2019). Through video capture of the behavior, statements, and/or demeanor of suspects and victims, BWCs may produce evidence that leads to improved case processing and outcomes for both victims and offenders (see Fan, 2017; Goodall, 2007; White, 2014). Stated differently, BWCs have the potential to both "implicate and exonerate" (White et al., 2019, p. 9), and yet despite this potential, few studies have examined the effect of BWCs on the prosecution and courts (see Lum et al., 2019; see more recently Williams et al., 2021), with even fewer published experimental assessments. Given that US State courts handle upwards of 15 million criminal cases each year (Court Statistics Project, 2020) and the adoption of BWCs continues to grow, understanding the impact of BWC footage on case outcomes is increasingly important. The current study adds to this limited body of research by analyzing court outcomes across various crime types following a 6-month cluster-randomized trial of BWCs in Miami Beach, Florida (within 12 months after the completion of the experiment).

\section{Background}

The potential for BWCs to provide evidence for case processing has been cited by researchers and practitioners since the early stages of the BWC movement (see Goodall, 2007; Merola et al., 2016; White, 2014). To date, however, research on the impacts of BWCs on court-related outcomes has been limited and inconclusive. Using experimental and quasi-experimental designs, respectively, Owens et al. (2014) and Morrow et al. (2016) found that domestic violence incidents attended by officers wearing BWCs were associated with increased criminal justice outcomes such as charges filed, prosecutions, plea agreements, and guilty verdicts, relative to comparison cases (see also Ellis et al., 2015). In a small-scale pilot study, Goodall (2007) noted increases in the 
proportion of criminal incidents leading to arrest following BWC implementation, and ODS Consulting (2011) found that criminal cases in a BWC pilot jurisdiction were more likely to be disposed of via early guilty plea when BWC video was used.

Yet, several methodologically rigorous studies have failed to find any effect of BWCs on court outcomes. Tracking the dispositions of misdemeanor drug and alcohol cases following a randomized controlled trial (RCT) in Tempe (AZ), White et al. (2019) noted no significant differences in guilty outcomes between BWC cases and control cases. Similarly, Yokum et al. (2017) found no significant differences in charges prosecuted, guilty pleas, or guilty verdicts between aggregate BWC cases and control cases following a RCT implemented with the Washington (DC) Metropolitan Police Department. However, Yokum et al. were unable to analyze incidents where the initial charge was amended by prosecutors. Additionally, Ariel et al. (2019) have noted spillover concerns when causal inferences are made from tests that suffer from treatment contamination or situations in which BWC officers are present at control incidents.

One potential explanation for these inconsistent results is that the effect of BWC video on court outcomes varies significantly by crime type. In domestic violence cases, for instance, BWC footage might better capture victim statements and visible injury (Morrow et al., 2016; Westera \& Powell, 2017), while in drug/alcohol cases, such footage might better capture the actions and demeanor of the suspect (see Groff et al., 2018; White et al., 2019), when compared to written reports or officer testimony alone. Other types of cases, such as crimes committed against police officers (i.e., assault and/ or battery of an officer, resisting arrest, etc.), may also benefit from the presence of BWCs, particularly if these offenses occur in direct view of the camera and thus provide an opportunity for the crime to be captured on video. Indeed, both qualitative and quantitative evidence suggests that the likelihood that prosecutors will view BWC video prior to charging decisions varies by crime type, with domestic violence, drug/alcohol, and battery of police officer/resisting arrest charges among the most frequently viewed offense categories (see Groff et al., 2018). To date, however, there has been no intra-jurisdictional comparison of court outcomes across these crime types, making it difficult to determine whether the inconsistency seen in prior research is influenced by crime type. Furthermore, existing studies have not yet assessed the impact of BWCs on the prosecution of crimes committed against police officers.

Our objective in this study was to examine whether BWCs affect the likelihood that a criminal charge will result in various forms of guilty outcomes, formal convictions, and declined prosecutions. The data $(\mathrm{N}=2,605)$ come from a 6-month randomized controlled trial implemented in partnership with the Miami Beach Police Department (MBPD) and the Bureau of Justice Assistance's Smart Policing Initiative (SPI) program conducted from January to June 2017. Given that prior BWC experiments have suffered from issues related to treatment contamination, such that treatment and control officers often respond to the same incidents (see Ariel et al., 2019), the current study attempts to limit this possibility by employing a cluster-randomized design in which discrete spatiotemporal units (i.e., geographic and temporal shifts) were randomly assigned to treatment (BWC) and control (no BWC) conditions. A partnership with the State Attorney's Office provided unique access to court processing information on experimental and control offenses. Our inferences and outcomes were concentrated at both the cluster and charge level, with specific focus on domestic violence charges, drug/alcohol charges, and crimes committed against police officers (e.g., assault or battery of a police 
officer, resisting arrest) as these cases are most likely to be affected by the presence of a camera. To our knowledge, this is the first test of the impact of BWCs on court outcomes across multiple crime types within the same jurisdiction. By comparing these outcomes within the same setting, we hope to provide stronger inferences regarding the potential for BWC evidence to vary in utility across crime types. Results of these analyses may have important implications for BWC policy at both the police and prosecutorial level.

\section{Study site}

Miami Beach spans an area of 7.63 square miles on the east coast of Florida. During 2017 (the year of the study period), Miami Beach had a residential population of approximately 91,000 people and was the 26th largest city in Florida. ${ }^{1}$ The residential population is over $50 \%$ Hispanic and $30 \%$ White, with a median income of roughly $\$ 54,000$, and a $14 \%$ poverty rate (US Census Bureau, 2021a; US Census Bureau, 2021b). Crime in Miami Beach is traditionally driven by an abundance of tourism, nightlife, and subsequent drug use/distribution, with over 8,000 index crimes per 100,000 population in 2019 (see Florida Department of Law Enforcement, 2019; Kurtz et al., 2009). The city is separated into four main squad areas corresponding to the north, central, south, and entertainment districts of the city. The north district encompasses the northernmost section of the city between 63rd street and 87th terrace. This area is mostly residential with a higher poverty rate than the rest of the city. The middle district extends from approximately 17th to 63rd street and is considered a wealthier residential area. The south district stretches from between 16th and 17th street in the north to the southern tip of the peninsula. This area contains most of the bars, clubs, and nightlife that the city is known for. Accordingly, the entertainment district lies within the south district, representing an area approximately two blocks wide and extending from 16th street in the north to 5th street in the south (Askew, 2021).

\section{Experimental design}

Thirty-nine police spatiotemporal units were randomly assigned to either treatment (BWCs) or control (no BWCs) conditions for a 6-month intervention period lasting from January 1, 2017, to June 11, 2017. Unlike previous experiments that have used police shifts (Ariel et al., 2015; Ariel et al., 2020), officers (Yokum et al., 2017), or spatial hotspots (Ariel, 2016), here we used a combination of time and space and officers. That is, geographic squad areas $(N=10)$ were combined with both specific shifts and specific days to form spatiotemporal units that were then randomly assigned to treatment or control. Thus, treatment and control units operated within the same geographic areas but did not operate simultaneously. Those assigned to the same area were assigned on different days or times, while those assigned during the same days and times were assigned to different areas. All general patrol locations/units were included in the study, with the exception of some specialty units (e.g., gang suppression, undercover, canine unit). Included squad areas comprised the south, middle, north, and entertainment sectors of the city, in addition to several smaller patrol beats

\footnotetext{
${ }^{1}$ Due to the consistent influx of tourism, however, the true population of Miami Beach at any given time far exceeds that of the residential population.
} 
within these areas. The day and shift components of the experiment involved sets of three successive days (e.g., Friday, Saturday, Sunday; Monday, Tuesday, Wednesday; Tuesday, Wednesday, Thursday) and separate shift assignments (day, afternoon, and midnights shifts). A full randomization table can be found in the Supplementary Materials.

At the moment of random assignment, the location, day, and shift were inseparable, representing a 3-way interaction. This interaction was natural to the MBPD's normal course of operations. Every 6 months, the MBPD shuffles the assignment of police officers into area/day/shift combinations in a process colloquially referred to as the "shift bid." Some officers stay in the same cluster over time while others rotate; however, the spatiotemporal units remain consistent throughout the 6-month period. Thus, during the experimental period, these units were mutually exclusive, such that no officer assigned to a BWC condition was also assigned to a control condition. Officers were required to be in their assigned geographic areas on the assigned days and times each week for the entirety of the intervention period.

In line with Campbell and Stanley's (1963; see also Ariel et al., 2022) recommendations, cluster randomization was chosen as to avoid treatment contamination and violation of the stable unit treatment value assumption (SUTVA) that may occur when BWC officers and control officers respond to the same incident (see Ariel et al., 2019; Rosenbaum, 2007). In other words, by randomly assigning BWCs to all police officers operating within the same geographic area, on the same days, and for the same shift, the potential for interaction between treatment and control groups should be limited. The population of spatiotemporal units in Miami Beach averaged roughly 5 officers $(M=$ $5.13)$ and 1,066 calls for service $(M=1,065.74)$ per cluster (Supplementary Materials).

Randomization of squad area/day/shift combinations was conducted with a simple random assignment generator, such that each unit had an equal chance of receiving treatment or control. This procedure resulted in 22 experimental clusters and 17 control clusters, with all officers in the experimental clusters being assigned BWCs and no officers in control clusters being assigned BWCs. BWCs were positioned on officers' uniforms, and officers had no discretion about when and how to use the BWCs, with a blanket policy of activation in all police-public engagements. Officers were instructed to activate their BWCs at the beginning of each call and to then categorize the call after completion. At the end of each shift, officers then uploaded any video that they captured when docking their BWC.

Treatment conditions were most common on Mondays, Tuesdays, and Wednesdays (24\% of experimental units), while control conditions were most common on Sundays, Mondays, and Tuesdays (29\% of control units). Additionally, experimental shifts were most commonly day shifts (38\% of shifts), and control shifts were most commonly afternoon shifts (35\% of shifts); however, there were no significant dependencies between experimental condition and day of the week $\left(\chi^{2}(6)=3.80, p=0.70\right)$ or shift assignment $\left(\chi^{2}(3)=3.67, p=0.95\right)$. Experimental and control groups also experienced similar levels of calls for service (CFS), with 20,949 total CFS in clusters with BWC assignment and 20,615 CFS in clusters without BWC assignment. However, squad areas without BWC assignment did experience higher average CFS $(M=1,212.65 ; S D$ $=594.46)$ than squad areas with BWC assignment $(M=952.23 ; S D=673.94)$ over the course of the study. The baseline comparability of the treatment and control clusters is shown in Table 1. 
Table. 1 Treatment and control cluster baseline characteristics

\begin{tabular}{lll}
\hline & Control & Treatment \\
\hline N of clusters & 17 & 22 \\
N of officers & 97 & 103 \\
All calls for service (CFS) & 20,615 & 20,949 \\
Mean per cluster (SD) & $1,212.65(594.46)$ & $952.23(673.94)$ \\
CFS-victim-initiated & 13,577 & 12,269 \\
Mean per cluster (SD) & $798.65(466.20)$ & $557.68(469.67)$ \\
CFS-police-initiated & 7,036 & 8,678 \\
Mean per cluster (SD) & $413.88(218.99)$ & $394.45(282.61)$ \\
\hline
\end{tabular}

\section{Study population and eligibility criteria}

The study population consisted of arrests initiated by police officers (proactively or reactively) and then sent to the local Florida prosecutor's office for review. Given our interest in assessing the evidentiary impact of BWCs on individual charge-level outcomes, with "charge" referring to an individual arrest/allegation, eligible clusters were required to have produced at least one criminal charge that was sent to the State Attorney's Office for prosecution and was disposed of during our follow-up period. This resulted in the exclusion of one experimental cluster which produced no prosecuted cases with recorded dispositions, leaving 38 remaining clusters available for analysis (21 treatments and 17 controls). ${ }^{2}$

Individual charge data were provided by the State Attorney's Office, who prosecutes all cases in Miami-Dade County, in partnership with the MBPD. This allowed us to capture information on incidents that occurred during the study period. Due to the small overall population size of clusters, cluster sample sizes were unequal, and in total, there were $2,779(M=73.13 ; S D=71.19$ per cluster $)$ charges that occurred across the 38 clusters, with $1,568(M=74.66 ; S D=74.61$ per cluster $)$ charges associated with BWC footage and 1,211 $(M=71.24 ; S D=68.96$ per cluster $)$ charges not associated with BWC footage.

For charges to be considered eligible for analysis, however, we required information on the arrest or filing charge description, the cluster that the incident originated from, whether the incident was attended by an officer wearing a BWC, and the final charge disposition. This led to the exclusion of 174 charges that were either missing arrest or filing information, were transferred to another court, resulted in a fugitive warrant, became consolidated with other cases, or resulted in a civil motion. Thus, there were $1,452(M=69.14 ; S D=69.53$ per cluster $)$ BWC charges considered valid for analysis and $1,153(M=67.82 ; S D=65.40$ per cluster $)$ control charges considered valid for analysis, resulting in a total valid sample size of 2,605 charges $(M=68.55 ; S D=66.81$ per cluster). Within this final sample, $54 \%$ of charges in experimental clusters were classified as misdemeanors, $44 \%$ were classified as felonies, and $2 \%$ were juvenile

\footnotetext{
2 The spatiotemporal unit that was excluded consisted of a day shift on Saturdays, Sundays, and Mondays within a smaller, lower crime, area of the city that was patrolled by only one officer.
} 
offenses. This did not significantly differ from control clusters, where $52 \%$ of charges were classified as misdemeanors, $46 \%$ were classified as felonies, and $2 \%$ were juvenile offenses $\left(\chi^{2}(2)=2.01, p=0.37\right){ }^{3}$ The CONSORT diagram in Figure 1 provides a detailed overview of the allocation, inclusion, follow-up, and analysis stages useful for understanding the flow of charges and the rationale for excluding certain observations. ${ }^{4}$

\section{Dependent and independent variables}

Several court-related outcome measures were employed to examine the evidentiary value of BWCs. Of primary importance is the causal inference between the presence of BWC footage at the charge-level and various guilty and not guilty outcomes. However, as separate outcomes, we also isolated formal convictions and charges that the State Attorney's Office declined to prosecute, which are likely to contain a separate set of causal mechanisms that affect decision-making processes.

Convictions + adjudication withheld We chose to aggregate convictions and adjudication withheld outcomes to represent the total sample of charges that involved enough evidence to find the defendant guilty. "Adjudication withheld" (Chiricos et al., 2007, p. 547 ) is a disposition in which evidence is deemed sufficient for a finding of guilt but where a formal conviction is deferred, often to provide the defendant with an opportunity to complete some court-imposed mandate such as probation (Hayes-Smith \& Hayes-Smith, 2009; Spohn et al., 1998). Convictions, however, include the formal finding of guilt through any means (e.g., jury trials, bench trials, and plea bargains). ${ }^{5}$ It is important to note that these outcomes are unique and have meaningful differences which should not be ignored. Given our focus on the potential for BWCs to produce evidence, however, the combination of these measures was intended to increase statistical power while still isolating cases in which evidence was deemed sufficient for a finding of guilty. ${ }^{6}$

\footnotetext{
${ }^{3}$ While our analyses were focused on the charge-level rather than the defendant or case-level, randomization appeared to be effective in equating the experimental and control groups on a number of factors known to influence court outcomes. The average number of charges per case was $1.67(S D=1.35)$ in control clusters and $1.67(S D=1.15)$ in experimental clusters, $t(1560)=0.09, p=0.93$. The average age of defendants in each case was 32.57 years $(S D=11.69)$ in control clusters and 32.95 years $(S D=11.32)$ in experimental clusters, $t(1560)=-0.65, p=0.52$. Additionally, $85.3 \%$ of the charges in control clusters were associated with male defendants and $87.1 \%$ of charges in experimental clusters were associated with male defendants, $\chi^{2}(1)=1.45$, $p=0.23$. It should be noted, however, that there was a significantly higher proportion of charges associated with Black defendants in experimental clusters than control clusters $(52.8 \%$ vs. $48.5 \%), \chi^{2}(1)=4.69, p=0.03$.

${ }^{4}$ The basic template for the CONSORT diagram can be found at http://www.consort-statement.org/consortstatement/flow-diagram

${ }^{5}$ We were often unable to identify the adjudicatory method through which charges were disposed of within the data and cannot say what proportion of convictions or adjudication withheld outcomes were reached via plea agreement, bench trial, jury trial, etc.

${ }^{6}$ As an illustrative example, we conducted sensitivity power analyses for independent proportions using $\mathrm{G}^{*}$ Power 3 (see Faul et al., 2007). Results suggested that to maintain a power level of 0.8 across all outcomes with an alpha level of 0.05 and a two-tailed test, the necessary effect sizes ranged from $h=0.13$ to $h=0.65$ for convictions alone, $h=0.13$ to $h=0.62$ for adjudication withheld outcomes alone, and $h=0.13$ to $h=0.61$ for adjudication withheld outcomes and convictions combined. Thus, combining these measures allowed for slight reductions in the effect sizes necessary to identify treatment effects while remaining theoretically consistent with the purposes of our study.
} 


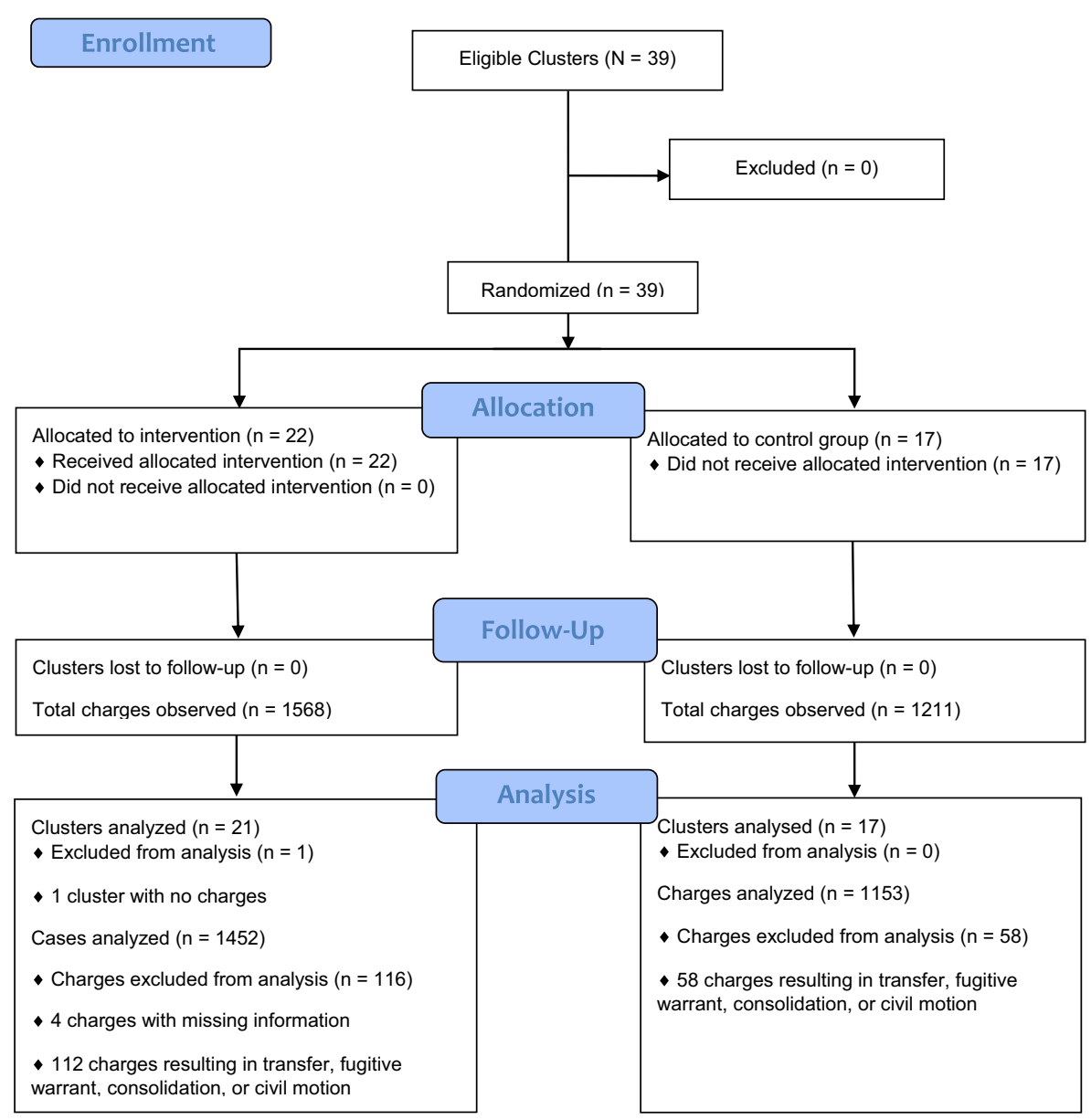

Figure 1. CONSORT diagram for BWC cluster and case

This aggregate measure was operationalized as a dichotomous variable $(1 / 0)$ contrasted against the outcomes of all other prosecutions that did not result in a guilty disposition, which included acquittals, dismissals, and charges that were nolle prossed (charges dropped by the prosecution). ${ }^{7}$ In total, $55.2 \%(n=433)$ of charges with sufficient evidence for a finding of guilt were classified as adjudication withheld, and approximately $95 \%(n=1,075)$ of the remaining charges were nolle prossed.

Convictions Given that the label of a formal conviction often creates a host of consequences related to voting, employment, and housing rights (see Hoskins, 2018), we also separated convictions from adjudication withheld outcomes as an additional subanalysis. Thus, convictions are a subset of our combined measure. In this instance, however, they represent a dichotomous variable that is contrasted against the outcomes of all other prosecuted charges rather than acquittals, dismissals, and nolle pros

\footnotetext{
${ }^{7}$ Charges in which no action was taken by prosecutors were not included in this variable and were instead treated as a distinct outcome.
} 
outcomes alone. In other words, we were interested in whether BWC charges were more or less likely to result in formal convictions as opposed to any other outcome (including adjudication withheld) once the State Attorney's Office decided to prosecute, so we could estimate the effect of BWC footage in such cases.

No action cases Our data contained information on incidents where no action was taken by the State Attorney's Office. These are arrests in which prosecution was declined, and given prior research suggesting that BWC footage may be an important predictor of prosecutors' filing decisions (see Groff et al., 2018), these charges were analyzed separately as a discrete outcome (i.e., charges filed vs. not filed).

Operationalization of crime type Outcome measures were examined for the full sample of charges, as well as separately for domestic violence charges, drug/alcohol charges, and crimes against police officers, given the stronger theoretical potential for BWC footage to be salient for these offenses. While domestic violence incidents could be identified directly, drug/alcohol charges and crimes against police officers are composite measures combining multiple charge descriptions. Drug/alcohol charges include various forms of intoxication, possession, and distribution/manufacturing, while crimes against police officers include assault and/or battery of a law enforcement officer and multiple forms of resisting arrest. In total, approximately $80 \%(n=719)$ of drug/alcohol charges involved possession of drugs, and approximately $82 \%(n=272)$ of crimes committed against police officers were classified as resisting arrest.

Presence of BWC The independent variable of interest is whether the criminal incident/ arrest sent to the State Attorney's Office for review was initiated by a responding officer who was wearing a BWC. More specifically, this is a measure of whether the incident occurred in a location and time where all patrol officers were assigned BWCs. It is possible that treatment incidents could have spilled over into control areas (or vice versa); however, a fidelity check indicated that all incidents considered valid for analysis were initiated by officers in the correct experimental condition. In total, all experimental incidents were attributable to $84 \%(n=87)$ of BWC officers, and all control incidents were attributable to $76 \%(n=74)$ of control officers.

Arrests in this context could be also considered either proactive or reactive. That is, an arrest could have been made during or shortly after a call took place, or alternatively, at a later point in time if there was a delay in reporting or an investigation was needed. Naturally, the more time that elapses between an incident and a police response, the less opportunity BWCs may have to capture material evidence of the crime. In total, approximately $96 \%$ of aggregate arrests, $95 \%$ of domestic violence arrests, $99 \%$ of drug/alcohol arrests, and $98 \%$ of arrests for crimes committed against police officers occurred on the same date as the offense. Additionally, the majority (53\%) of eligible BWC charges began as officer initiated CFS. Taken together these results suggest that officers were in close spatial and temporal proximity to the offenses represented in our analyses.

Despite this, it should be noted that our independent variable is not a direct measure of whether a BWC produced meaningful evidence or whether the resulting footage was formally or informally used by the State Attorney's Office during filing decisions, criminal hearings, trials, plea negotiations, or other judicial processes (addressing this 
question requires a critical review of the footage itself, which was outside the scope of this study, and would provide data on the treatment arm of the experiment only). Across the full sample, $55.7 \%(n=1,452)$ of charges were initiated by an officer wearing a BWC, and $44.3 \%(n=1,153)$ of charges were not. Bivariate frequencies and cross tabulations between our dependent and independent variables can be seen in Table 2 .

\section{Statistical methods}

We first examined whether there were statistically significant differences in the bivariate frequencies for each outcome measure between BWC charges and control charges (Table 2). Multilevel logistic regression analyses were then used to estimate the effect of BWC video on charge outcomes while accounting for the cluster-level variance (i.e.,

Table. 2 Bivariate frequencies and proportions

\begin{tabular}{|c|c|c|c|}
\hline & Control & Treatment & $p$-value \\
\hline \multicolumn{4}{|l|}{ All charges $(N=2,605)$} \\
\hline Conviction + adj. withheld & $361(41.7 \%)$ & $423(40.3 \%)$ & 0.535 \\
\hline Acquittal, dismissal, and nolle pros & $505(58.3 \%)$ & $627(59.7 \%)$ & 0.535 \\
\hline Conviction & $153(17.7 \%)$ & $198(18.9 \%)$ & 0.503 \\
\hline No action & $287(24.9 \%)$ & $402(27.7 \%)$ & 0.108 \\
\hline \multicolumn{4}{|l|}{ Domestic violence $(N=138)$} \\
\hline Conviction + adj. withheld & $4(8.5 \%)$ & $6(14.6 \%)$ & 0.504 \\
\hline Acquittal, dismissal, and nolle pros & $43(91.5 \%)$ & $35(85.4 \%)$ & 0.504 \\
\hline Conviction & $1(2.1 \%)$ & $6(14.6 \%)$ & $0.047 *$ \\
\hline No action & $21(30.9 \%)$ & $29(41.4 \%)$ & 0.198 \\
\hline \multicolumn{4}{|l|}{ Crimes against officers $(N=331)$} \\
\hline Conviction + adj. withheld & $34(29.8 \%)$ & $63(44.1 \%)$ & $0.019 *$ \\
\hline Acquittal, dismissal, and nolle pros & $80(70.2 \%)$ & $80(55.9 \%)$ & $0.019 *$ \\
\hline Conviction & $20(17.5 \%)$ & $29(20.3 \%)$ & 0.579 \\
\hline No action & $23(16.8 \%)$ & $51(26.3 \%)$ & $0.041 *$ \\
\hline \multicolumn{4}{|l|}{ Drugs/alcohol $(N=899)$} \\
\hline Conviction + adj. withheld & $122(45.9 \%)$ & $160(39 \%)$ & $0.078^{+}$ \\
\hline Acquittal, dismissal, and nolle pros & $144(54.1 \%)$ & $250(61 \%)$ & $0.078^{+}$ \\
\hline Conviction & $48(18 \%)$ & $61(14.9 \%)$ & 0.274 \\
\hline No action & $88(24.9 \%)$ & $135(24.8 \%)$ & 0.976 \\
\hline
\end{tabular}

Notes: Parentheses reflect column percentages based on binary variable groupings. No action charges are compared against all charges in which action was taken. Conviction and adjudication withheld outcomes are compared against acquittal, dismissal, and nolle pros outcomes (and vice versa). Proportions do not sum to $100 \%$ as outcomes are not mutually exclusive. Due to low expected cell counts, Fisher's exact tests were used for domestic violence convictions and adjudication withheld outcomes; all other p-values reflect $\chi^{2}$ statistics estimated from independent samples proportion tests

Abbreviations: ${ }^{+} \mathrm{p}<.10,{ }^{*} \mathrm{p}<.05$ 
the variance attributable to the spatiotemporal unit). ${ }^{8}$ Before estimating these models, we conducted likelihood ratio tests to confirm that there was significant variation in court outcomes across experimental clusters. To do so, we compared the log-likelihood of our unconditional multilevel models to those of standard logistic regression models containing no covariates. ${ }^{9}$ Our independent variable representing the presence/absence of a BWC was then added to these models as a fixed effect, while squad area remained as a random effect (varying intercept). The final specification of our multilevel models is represented by the following two-level equation (see Johnson, 2010):

$$
\begin{gathered}
\eta_{i j}=\beta_{0 j}+\beta_{1} B W C_{i j} \\
\beta_{0 j}=\gamma_{00}+\mu_{0 j}
\end{gathered}
$$

Here $\eta_{i j}$ represents the log odds of a given court outcome, $\beta_{0 j}$ is the intercept for each squad area/day/shift combination (which is our unit of assignment), and $\beta_{1}$ represents the fixed effect regression coefficient for BWCs. At the second level of the equation, the cluster-level intercepts $\left(\beta_{0 j}\right)$ are comprised of both the overall intercept across clusters $\left(\gamma_{00}\right)$ and the random variance of the intercepts for each cluster $\left(\mu_{0 j}\right)$. This model became our primary analytical approach; however, due to the low overall incidence of domestic violence convictions, we analyzed this outcome using a negative binomial regression model. ${ }^{10}$ In other words, for this outcome, we compared the count of domestic violence convictions between experimental and control area/day/shift combinations. As such, this effect was analyzed at the cluster level, and therefore, the results pertain only to the clusters as opposed to the individual charges. All analyses were conducted in $\mathrm{R}$ statistical software, with multilevel models estimated using the lme4 (Bates et al., 2015) and lmerTest packages (Kuznetsova et al., 2017).

For logistic regression models, odds ratios were used as measures of effect size (see Chen et al., 2010), and the intraclass correlation coefficients (ICC) were calculated using the latent variable approach (see Snijders \& Bosker, 2012), which uses the variance estimate of the standard logistic regression model as the level 1 error term. For the negative binomial regression model (domestic violence convictions), the effect size is represented by the incident rate ratio (see Wilson, 2021). While the unit of analysis in this model is the cluster, an ICC value was calculated using the method

\footnotetext{
${ }^{8}$ Logistic regression models with cluster robust standard errors were also estimated. There were no substantive differences between the results of the multilevel models and the models with robust standard errors.

${ }^{9}$ There were four outcomes that did not demonstrate significant variance across clusters. These outcomes were convictions or adjudication withheld outcomes for crimes against officers $\left(\chi^{2}=0.88, p=0.347\right)$, convictions for crimes against officers $\left(\chi^{2}=0.081, p=0.776\right)$, no action outcomes for domestic violence charges $\left(\chi^{2}=\right.$ $0.054, p=0.816)$, and no action outcomes for drug/alcohol cases $\left(\chi^{2}=3.17, p=0.075\right)$. Nonetheless, we still chose to report the results for these outcomes using multilevel models, both to remain consistent with the design of the experiment and to increase reporting homogeneity across outcomes. Additionally, standard logistic regression models were estimated for these outcomes and indicated no substantive differences from our multilevel models.

${ }^{10}$ A likelihood ratio test for overdispersion indicated that a negative binomial model should be used by rejecting the null hypothesis that the Poisson model was not overdispersed $\left(\chi^{2}=24.29, \mathrm{df}=1, p<.001\right)$.
} 
described by Tseloni and Pease (2003), which divides the random effects variance of an unconditional mixed model by the sum of this variance and the dispersion parameter. As we noted, our cluster sample sizes varied across crime types and statistical tests, as not all clusters produced cases corresponding to each crime type. While there is debate surrounding the number of clusters needed to produce unbiased estimates in a multilevel model, research has suggested that this technique can be used with as few as 10 groups (see Bell et al., 2014; Raudenbush \& Bryk, 2002), fewer than the minimum number of clusters we included in a single analysis $(n=24)$.

\section{Results}

In total, $30.1 \%(n=784)$ of charges resulted in conviction or adjudication witheld outcomes, while $43.5 \%(n=1,132)$ of charges resulted in acquittal, dismissal, or nolle pros, and $26.4 \%(n=689)$ of charges were declined prosecution. Additionally, only $13.5 \%(n=351)$ of the total sample of charges resulted in a formal criminal conviction. As can be seen in Table 2, when a BWC was present (as opposed to not present), a significantly higher proportion of domestic violence charges resulted in a conviction $(14.6 \%$ vs. $2.1 \%, p=.047)$, even though the base rate for convictions in both treatment and control groups was very low.

Crimes committed against police officers wearing BWCs also experienced a significantly higher proportion of combined conviction and adjudication withheld outcomes than crimes committed against control officers (44.1\% vs. $29.8 \%, p=.014)$. However, crimes committed against officers wearing BWCs also resulted in no action dispositions (i.e., declined prosecution) in a significantly higher proportion of cases than crimes committed against control officers $(26.3 \%$ vs. $16.8 \%, p=.041)$.

No other significant bivariate differences were found, though drug/alcohol charges attended by control officers resulted in conviction or adjudication withheld outcomes at a notably higher rate than drug/alcohol charges attended by BWC officers, based on a .10 significance threshold $(45.9 \%$ vs. $39 \%, p=.078)$.

Table 3 displays the effect estimates based on our multilevel logistic and negative binomial regression models. No significant effects of BWC presence were found across aggregate crime measures, domestic violence measures, or drug/alcohol measures. However, after accounting for the cluster-level variance, crimes against police officers were significantly more likely to result in conviction or adjudication withheld outcomes when a BWC was present $(\beta=0.66, p=0.029$, OR $=1.93,95 \%$ CI $[1.09,3.76])$. Specifically, when prosecuted by the State Attorney's Office, the odds of a conviction or adjudication withheld outcome were $93 \%$ greater for charges in which a BWC was present than for charges in which a BWC was not present. $^{11}$

\footnotetext{
${ }^{11}$ In footnote 3 we cited evidence of a significant bivariate difference in the racial composition of BWC and non-BWC defendants. As a sensitivity analysis, we added race (Black/White/Other) as a covariate to the model predicting conviction or adjudication withheld outcomes for crimes against police officers. BWCs remained a significant predictor of conviction or adjudication withheld outcomes in this model $(\mathrm{OR}=1.95$, $95 \%$ CI $[1.07,3.55], p=0.03)$. Additionally, results remained statistically significant when controlling for the race and age of the defendant, as well as the severity of the current charge (misdemeanor/felony) and the total number of charges in each case $(\mathrm{OR}=2.04,95 \%$ CI $[1.07,3.89], p=0.03)$.
} 
Table. 3 Effect estimates for BWC footage and court outcomes after accounting for cluster effects

\begin{tabular}{|c|c|c|c|c|c|c|c|}
\hline & \multirow[b]{2}{*}{ Estimate } & \multicolumn{6}{|c|}{ Fixed effects: camera vs. no camera charges } \\
\hline & & SE & $p$-value & OR/IRR $[95 \% \mathrm{CI}]$ & $N$ clusters & $N$ obs. & $\mathrm{ICC}$ \\
\hline \multicolumn{8}{|l|}{ All charges } \\
\hline Conviction + adj. withheld & -0.12 & 0.20 & 0.544 & $0.89[0.60,1.30]$ & $38(21 \mathrm{~T}, 17 \mathrm{C})$ & 1916 & 0.055 \\
\hline Conviction & 0.002 & 0.26 & 0.995 & $1.00[0.61,1.65]$ & $38(21 \mathrm{~T}, 17 \mathrm{C})$ & 1916 & 0.093 \\
\hline No action & 0.10 & 0.12 & 0.383 & $1.11[0.88,1.40]$ & $38(21 \mathrm{~T}, 17 \mathrm{C})$ & 2605 & 0.01 \\
\hline \multicolumn{8}{|l|}{ Domestic violence } \\
\hline Conviction + adj. withheld & -0.54 & 1.56 & 0.727 & $0.58[0.03,12.25]$ & $24(13 \mathrm{~T}, 11 \mathrm{C})$ & 88 & 0.484 \\
\hline Conviction $^{\mathrm{a}}$ & 1.58 & 2.15 & 0.462 & $4.86[0.07,327.13]^{\mathrm{b}}$ & $38(21 \mathrm{~T}, 17 \mathrm{C})$ & 88 & 0.999 \\
\hline No action & 0.5 & 0.4 & 0.21 & $1.65[0.75,3.62]$ & $26(15 \mathrm{~T}, 11 \mathrm{C})$ & 138 & 0.015 \\
\hline \multicolumn{8}{|l|}{ Crimes against officers } \\
\hline Conviction + adj. withheld & 0.66 & 0.3 & $0.029 *$ & $1.93[1.07,3.48]$ & $32(17 \mathrm{~T}, 15 \mathrm{C})$ & 257 & 0.032 \\
\hline Conviction & 0.21 & 0.36 & 0.558 & $1.23[0.61,2.49]$ & $32(17 \mathrm{~T}, 15 \mathrm{C})$ & 257 & 0.016 \\
\hline No action & 0.56 & 0.38 & 0.139 & $1.74[0.83,3.65]$ & $33(18 \mathrm{~T}, 15 \mathrm{C})$ & 331 & 0.095 \\
\hline \multicolumn{8}{|l|}{ Drug/alcohol } \\
\hline Conviction + adj. withheld & -0.24 & 0.24 & 0.307 & $0.78[0.49,1.25]$ & $35(19 \mathrm{~T}, 16 \mathrm{C})$ & 676 & 0.042 \\
\hline Conviction & 0.002 & 0.39 & 0.996 & $1.00[0.46,2.16]$ & $35(19 \mathrm{~T}, 16 \mathrm{C})$ & 676 & 0.132 \\
\hline No action & -0.13 & 0.23 & 0.579 & $0.88[0.56,1.38]$ & $35(19 \mathrm{~T}, 16 \mathrm{C})$ & 899 & 0.025 \\
\hline
\end{tabular}

Notes: $\mathrm{T}$ and $\mathrm{C}$ denote the number of treatment and control clusters for each dependent variable

${ }^{a}$ Negative binomial regression model treating squad area/shift/day (i.e., spatiotemporal cluster) as the unit of analysis

${ }^{\mathrm{b}}$ Incident rate ratio

$* p<.05$

When considering the clustering effects, however, domestic violence convictions and no action outcomes for crimes against police officers do not retain the significant relationships seen in the bivariate analysis. Of note, all domestic violence convictions in which a BWC was present occurred within the same experimental cluster. Likely as a result of this, and the small domestic violence sample size, the ICC values for domestic violence convictions and combined conviction and adjudication withheld outcomes are very large. Given that nearly all of the total variance in these outcomes can be attributed to the between-cluster variance, we are unable to suggest with confidence that there is an effect of BWC footage on the outcomes of these charges.

Figure 2 further illustrates these findings by plotting the average marginal effects from our regression models. Though domestic violence convictions appear to experience the largest effect, the confidence intervals for this prediction are considerable. In contrast, the probability of a conviction or adjudication withheld outcome for crimes against police officers remains positive and does not overlap with the no-effect line, indicating that the presence of a camera in these cases significantly increases the probability of this combined outcome measure. 


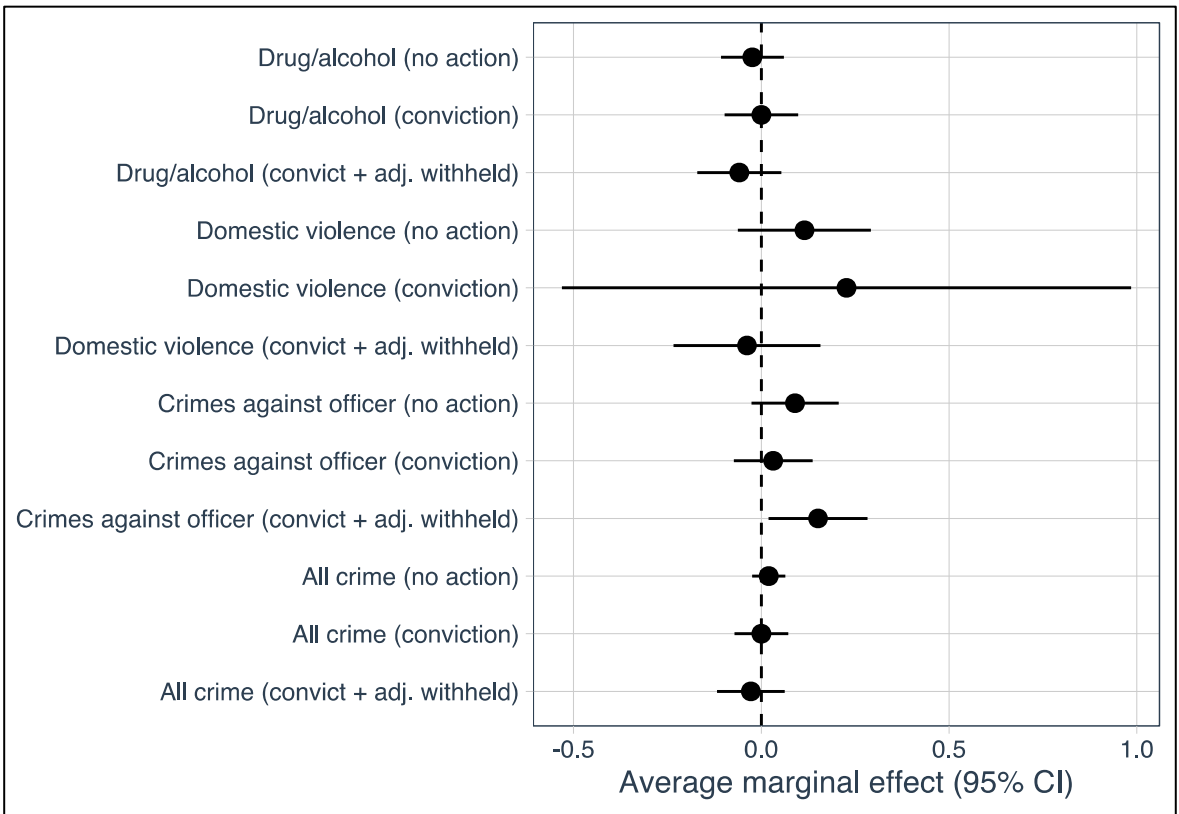

Figure 2. Marginal effects of BWCs on court outcomes

\section{Discussion and limitations}

Following a 6-month cluster-randomized trial in Miami Beach (FLA), this study uses 12 months of follow-up data provided by the State Attorney's Office to examine the effect of BWCs on court outcomes across various types of criminal charges in a single jurisdiction. Our results suggest that, for the prosecution of crimes against police officers (assault/battery of an officer, resisting arrest), BWCs led to a $93 \%$ increase in the odds of a conviction or adjudication withheld outcome relative to control charges. Such a finding is likely not unexpected, as BWCs are in a unique position to capture the characteristics of the offense in these situations given that these crimes are committed against the camera wearer. However, this finding is interesting given that many BWC proponents envisioned this technology leading to an increased likelihood of successful prosecution for crimes committed by police officers rather than crimes committed against police officers (see Mateescu et al., 2016; Smith, 2019). While we are unable to identify any specific prosecutions of police officers in our data, future studies should examine these cases and contrast them with the prosecution of crimes committed against police officers.

Regarding crimes committed against police officers, we also note mixed evidence of a higher proportion of BWC cases being declined prosecution. Such a finding, when taken in light of the significantly greater odds of combined convictions and adjudication withheld outcomes for these charges, would seem to be consistent with the proposition that BWCs can lead to fewer but stronger prosecutions (see Groff et al., 2018; Grossmith et al., 2015; White et al., 2019). If true, this would suggest that BWCs have the ability to provide objective evidence that is beneficial to all parties involved in a criminal case. However, caution is urged when interpreting this effect, given that it 
did not remain significant after adjusting for the variance in declined prosecutions at the cluster level.

Our findings concerning the effect of BWCs on domestic violence charges should also be considered promising yet not definitive. There was a significantly higher bivariate proportion of domestic violence charges in which a BWC was present that resulted in a conviction, relative to control charges. However, the sample sizes were small, and we could not separate the impact of the BWCs from the impact of the spatiotemporal unit for this outcome. The bivariate analyses offer insight that suggests a strong treatment effect for domestic violence charges that are otherwise difficult to prosecute (Westera \& Powell, 2017). On the other hand, we lacked sufficient statistical power to identify this effect, given the limited base rates (Hinkle et al., 2013). More research on these outcomes is needed, particularly with larger sample sizes and rigorous methodologies.

Additionally, we failed to identify a significant impact of BWCs on the outcomes of drug/alcohol charges. Such offenses often require police officers to identify subjective signs of intoxication (see White et al., 2019) or may even involve allegations of fabricated evidence (see Fan, 2017), thus providing theoretical rationale to believe that BWCs would prove useful during prosecution. However, our statistically nonsignificant findings for these charges are consistent with those of White et al. (2019). It is perhaps possible that BWCs can provide evidence of intoxication but not provide evidence of drug/alcohol possession, or vice versa. One hypothesis may be that intoxicated suspects are more likely to confront officers, as alcohol is linked to an intensified perception of self-righteousness and false accusation of police officers' wrongdoing (Denton \& Krebs, 1990); however, we find no evidence for this claim. While suspects may become more belligerent while intoxicated, BWCs do not seem to affect these circumstances one way or another, and we were unable to make these distinctions in our data. Future analyses should attempt to determine if the effects of BWCs differ based on these more specified situations.

Additional caveats deserve attention in future research. First, we are unable to show if and how BWC footage was viewed and used by prosecutors nor do we have an indepth understanding of the ways in which police investigators use BWC content to support the case against defendants. While prior research suggests that, in the majority of cases where a charge is filed, BWC footage will be viewed at some point during case processing (Groff et al., 2018), the specific mechanisms that lead to these observed effects are presently unknown. Future research in this area would benefit from measures of viewing and usage rates, as well as information regarding when and how BWC footage is used throughout the court process, particularly across various offense types (e.g., how BWC footage is actively used during plea negotiations, case preparation, trials, motions to suppress, etc. and how this may vary by crime type.). Future RCTs conducted in collaboration with local prosecutor's offices should strive to capture some of these measures to explore mediating factors within a randomized controlled framework. This may allow researchers to examine what happens in-between BWC assignment and the downstream effects that they observe.

Despite this limitation, however, it is often necessary to first establish that an intervention may have a true effect in order to provide a basis for more specific analyses on the mechanisms behind that effect. While we are unable to speak directly to what transpired between the random assignment of BWCs and the effects that we observed, 
our methodological approach allows us to reasonably infer that the observed effect was set in motion by the BWC assignment (see discussion in Weisburd, 2003). Additionally, sensitivity analyses (see footnote 11) supported our main findings while holding constant a number of demographic and case-level variables often thought to influence court outcomes. Nonetheless, this "black box" (Famega et al., 2017, p. 106) issue is not uncommon in experimental criminology, where it is often not possible to explain the factors that mediate the relationship between a treatment and an effect (Green et al., 2010).

In addition, some outcomes were not statistically significant at the usual statistical thresholds once the clustering effect was taken into account. As noted, this presents a statistical power consideration; however, null findings for several outcome measures (but not in others) do not necessarily indicate a lack of effect. For example, given that BWC footage may benefit both the prosecution and defense, it is possible that these effects cancel each other out in the aggregate. The discussion should then be about targeting areas of law enforcement in which the intervention is the most likely to have the strongest desirable effect. While we are presently unable to examine these possibilities, future research should explore these underlying causal mechanisms to determine with more specificity the settings in which BWC footage impacts, or fails to impact, court outcomes. Such research may benefit from being conducted at a more individual level, perhaps using case studies or court observations to examine how often (and the ways in which) BWCs benefit both the prosecution and the defense.

A related limitation is that we are currently unable to distinguish between outcomes achieved via plea agreement and those achieved via trial verdict. While it has been well documented that plea bargains account for over $95 \%$ of all convictions in state and federal courts (Bureau of Justice Statistics, 2010, 2015), the impact of BWCs on particular adjudicatory methods remains an important area for future research. Qualitative interviews with legal actors suggest that BWC footage may not only increase plea negotiations at early processing stages (Todak et al., 2018), but may also play an important role in cases that do progress to trial (see Gaub et al., 2020). Thus, we encourage future research to explore the effect of BWC evidence on both the frequency of certain adjudicatory processes and the outcomes of these processes with as much specificity as possible. However, doing so may also require extended follow-up periods. Our sample of charges represents only those that reached disposition during a 12-month post-intervention period, and we are currently unable to determine how many charges were still pending or whether the outcomes of these charges would differ from those in our sample. Follow-up periods of multiple years may be needed, particularly given the lengthy nature of case processing.

Finally, it is possible that the clusters of officers and the incidents they responded to in our study differ from those that are typical in other areas, as Miami Beach is unlike many other police jurisdictions (given its uber-active nighttime economy and large transient population during holiday seasons). Given that our study took place in a single city with limited sample sizes for several outcome measures, more research of this nature is needed. 


\section{Conclusions}

Despite these limitations, the results of this study are not without important theoretical and policy implications. The nonsignificant relationship between BWCs and aggregate case outcomes coupled with the significant (albeit limited) effects found in the crime type analyses suggests that the utility of BWC evidence is nuanced. In other words, the effect of BWC footage on case outcomes may indeed be dependent on the nature of the crime. From a theoretical perspective, this is only logical, as crimes that are often characterized by delayed discovery or reporting (e.g., residential property theft or burglary) are unlikely to benefit from the unique ability of BWCs to record events as they unfold or in their immediate aftermath.

From a policy perspective, however, the implications are that both police and prosecutors may be able to better utilize BWC footage if they are focused on the specific situations in which footage is likely to be useful. Many have expressed concern with the increased workload and time commitment that BWCs place on legal actors (see Gaub et al., 2020; Groff et al., 2018; Merola et al., 2016; Todak et al., 2018). Understanding the effect of BWC footage on court outcomes with greater specificity given to crime types and adjudicatory processes may allow police to make more informed decisions when tagging evidence and allow prosecutors to prioritize cases when reviewing video. As the specificity of these findings increases, potential policy options regarding video capture, tagging, and viewing can become increasingly evidence based. Ultimately, such findings may help jurisdictions to better manage large amounts of BWC footage while still using them to improve criminal justice outcomes.

Our strongest conclusion should therefore be that equipping frontline officers with BWCs may cause variations in some criminal justice system outcomes, compared to a policy of not equipping frontline officers with BWCs. However, the evidentiary effects of BWCs appear to differ by offense type, and future research is needed to test the generalizability of this claim and the mechanisms behind it. Ultimately, only through understanding these effects can the adoption and implementation of BWCs be better informed at a jurisdictional level.

Supplementary Information The online version contains supplementary material available at https://oi. org/10.1007/s11292-021-09479-6.

Funding This project was supported by the Bureau of Justice Assistance's Smart Policing Initiative program under Grant \#2015-WY-BX-002.

Open Access This article is licensed under a Creative Commons Attribution 4.0 International License, which permits use, sharing, adaptation, distribution and reproduction in any medium or format, as long as you give appropriate credit to the original author(s) and the source, provide a link to the Creative Commons licence, and indicate if changes were made. The images or other third party material in this article are included in the article's Creative Commons licence, unless indicated otherwise in a credit line to the material. If material is not included in the article's Creative Commons licence and your intended use is not permitted by statutory regulation or exceeds the permitted use, you will need to obtain permission directly from the copyright holder. To view a copy of this licence, visit http://creativecommons.org/licenses/by/4.0/. 


\section{References}

Ariel, B. (2016). Increasing cooperation with the police using body worn cameras. Police Quarterly, 19(3), 326-362. https://doi.org/10.1177/1098611116653723.

Ariel, B., Farrar, W. A., \& Sutherland, A. (2015). The effect of police body-worn cameras on use of force and citizens' complaints against the police: A randomized controlled trial. Journal of Quantitative Criminology, 31(3), 509-535. https://doi.org/10.1007/s10940-014-9236-3.

Ariel, B., Sutherland, A., Henstock, D., Young, J., Drover, P., Sykes, J., et al. (2017). "Contagious accountability" a global multisite randomized controlled trial on the effect of police body-worn cameras on citizens' complaints against the police. Criminal Justice and Behavior, 44(2), 293-316. https://doi.org/ $10.1177 / 0093854816668218$.

Ariel, B., Sutherland, A., \& Sherman, L. W. (2019). Preventing treatment spillover contamination in criminological field experiments: The case of body-worn police cameras. Journal of Experimental Criminology, 15(4), 569-591.

Ariel, B., Mitchell, R. J., Tankebe, J., Firpo, M. E., Fraiman, R., \& Hyatt, J. M. (2020). Using wearable technology to increase police legitimacy in Uruguay: the case of body-worn cameras. Law \& Social Inquiry, 45(1), 52-80. https://doi.org/10.1017/1si.2019.13.

Ariel, B., Bland, M. P., \& Sutherland, A. (2022). Experimental Designs. SAGE Publications.

Askew, S. (2021). Key components of mayor's plan to overhaul Miami Beach's entertainment district approved. RE Miami Beach. https:/www.remiamibeach.com/south-beach/key-components-of-mayorsplan-to-overhaul-miami-beachs-entertainment-district-approved/

Bates, D., Maechler, M., Bolker, B., \& Walker, S. (2015). Fitting linear mixed-effects models using lme4. Journal of Statistical Software, 67(1), 1-48. https://doi.org/10.18637/jss.v067.i01.

Bell, B. A., Morgan, G. B., Schoeneberger, J. A., Kromrey, J. D., \& Ferron, J. M. (2014). How low can you go? Methodology, 10, 1-11. https://doi.org/10.1027/1614-2241/a000062.

Bureau of Justice Statistics. (2010). Felony defendants in large urban counties, 2006 - statistical tables. US Department of Justice.

Bureau of Justice Statistics. (2015). Federal justice statistics, 2012 - statistical tables (NCJ Report No. 248470). Washington D.C.: U.S. Department of Justice.

Campbell, D. T., \& Stanley, J. C. (1963). Experimental and quasi-experimental designs for research on teaching. In N. L. Gage (Ed.), Handbook of research on teaching (pp. 171-246). Rand McNally.

Chen, H., Cohen, P., \& Chen, S. (2010). How big is a big odds ratio? Interpreting the magnitudes of odds ratios in epidemiological studies. Communications in Statistics - Simulation and Computation, 39(4), 860-864. https://doi/org/10.1080/03610911003650383

Chiricos, T., Barrick, K., Bales, W., \& Bontrager, S. (2007). The labeling of convicted felons and its consequences for recidivism. Criminology, 45(3), 547-581. https://doi.org/10.1111/j.1745-9125.2007. 00089.x.

ODS Consulting (2011). Body worn video projects in Paisley and Aberdeen, self- evaluation. Retrieved from bwvsg.com/wp-content/uploads/2013/07/BWV-Scottish-Report.pdf

Coudert, F., Butin, D., \& Le Métayer, D. (2015). Body-worn cameras for police accountability: Opportunities and risks. Computer Law and Security Review, 31(6), 749-762.

Court Statistics Project (2020). State court caseload digest: 2018 data. National Center for State Courts. Retrieved from http://www.courtstatistics.org/_data/assets/pdf_file/0014/40820/2018-Digest.pdf.

Denton, K., \& Krebs, D. (1990). From the scene to the crime: The effect of alcohol and social context on moral judgment. Journal of Personality and Social Psychology, 59(2), 242.

Ellis, T., Jenkins, C., \& Smith, P. (2015). Evaluation of the introduction of personal issue body worn video cameras (Operation Hyperion) on the Isle of Wight: Final report to Hampshire constabulary. Portsmouth, England: Institute of Criminal Justice Studies, University of Portsmouth. Retrieved from port.ac.uk/media/contacts-and-departments/icjs/downloads/Ellis-Evaluation-Worn-Cameras.pdf

Famega, C., Hinkle, J. C., \& Weisburd, D. (2017). Why getting inside the "black box" is important: Examining treatment implementation and outputs in policing experiments. Police Quarterly, 20(1), 106-132. https://doi.org/10.1177/1098611116664336.

Fan, M. D. (2017). Justice visualized: Courts and the body camera revolution. UCDL Review, 50, 897.

Faul, F., Erdfelder, E., Lang, A. G., \& Buchner, A. (2007). G* Power 3: A flexible statistical power analysis program for the social, behavioral, and biomedical sciences. Behavior Research Methods, 39(2), 175191. https://doi.org/10.3758/BF03193146.

Florida Department of Law Enforcement (2019). County and municipal offense report. Retrieved from https:// www.fdle.state.fl.us/FSAC/UCR/2019/County_and_Municipal_Offense_Report_2019A.aspx 
Friedman, U. (2015). Do police body cameras actually work? The Atlantic. Retrieved from: http://www. theatlantic.com/international/archive/2014/12/do-police-body-cameraswork-ferguson/383323/

Gaub, J. E., Naoroz, C., \& Malm, A. (2020). Police BWCs as 'neutral observers': Perceptions of public defenders. Policing: A Journal of Policy and Practice. https://doi.org/10.1093/police/paaa067.

Goodall, M. (2007). Guidance for the police use of body-worn video devices: Police and crime standards directorate. London, U.K.: Home Office. Retrieved from library.college.police.uk/docs/homeoffice/ guidance-body-worn-devices.pdf.

Goodison, S., Davis, R., \& Wilson, T. (2018). Costs and benefits of body-worn camera deployment. Washington D.C.: Police Executive Research Forum. Retrieved from https:/www.policeforum.org/ assets/BWCCostBenefit.pdf

Green, D. P., Ha, S. E., \& Bullock, J. G. (2010). Enough already about "black box" experiments: Studying mediation is more difficult than most scholars suppose. The Annals of the American Academy of Political and Social Science, 628(1), 200-208. https://doi.org/10.1177/0002716209351526.

Groff, E. R., Ward, J. T., \& Wartell, J. (2018). The role of body-worn camera footage in the decision to file. Report for the Laura and John Arnold Foundation. Philadelphia, PA: Criminal Justice Department, Temple University.

Grossmith, L., Owens, C., Finn, W., Mann, D., Davies, T., \& Baika, L. (2015). Police, camera, evidence: London's cluster randomised controlled trial of body worn video. College of Policing.

Hayes-Smith, J., \& Hayes-Smith, R. (2009). Race, racial context, and withholding adjudication in drug cases: A multilevel examination of juvenile justice. Journal of Ethnicity in Criminal Justice, 7(3), 163-185. https://doi.org/10.1080/15377930903140300.

Hinkle, J. C., Weisburd, D., Famega, C., \& Ready, J. (2013). The problem is not just sample size: The consequences of low base rates in policing experiments in smaller cities. Evaluation Review, 37(3-4), 213-238.

Hoskins, Z. (2018). Criminalization and the collateral consequences of conviction. Criminal Law and Philosophy, 12(4), 625-639. https://doi.org/10.1007/s11572-017-9449-2.

Hyland, S. S. (2018). Body-worn cameras in law enforcement agencies, 2016. Washington, DC. U.S. Department of Justice, Office of Justice Programs, Bureau of Justice Statistics.

Jennings, W. G., Lynch, M. D., \& Fridell, L. A. (2015). Evaluating the impact of police officer body-worn cameras (BWCs) on response-to-resistance and serious external complaints: Evidence from the Orlando police department (OPD) experience utilizing a randomized controlled experiment. Journal of Criminal Justice, 43(6), 480-486. https://doi.org/10.1016/j.jcrimjus.2015.10.003.

Johnson, B. D. (2010). Multilevel analysis in the study of crime and justice. In A. R. Piquero \& D. Weisburd (Eds.), Handbook of quantitative criminology (pp. 615-648). Springer.

Kurtz, S. P., Inciardi, J. A., \& Pujals, E. (2009). Criminal activity among young adults in the club scene. Law Enforcement Executive Forum, 9(2), 47-59.

Kuznetsova, A., Brockhoff, P. B., \& Christensen, R. H. B. (2017). lmerTest package: Tests in linear mixed effects models. Journal of Statistical Software, 82(13), 1-26. https://doi.org/10.18637/jss.v082.i13.

Lum, C., Stoltz, M., Koper, C. S., \& Scherer, J. A. (2019). Research on body-worn cameras: What we know, what we need to know. Criminology \& Public Policy, 18(1), 93-118. https://doi.org/10.1111/1745-9133. 12412.

Lum, C., Koper, C. S., Wilson, D. B., Stoltz, M., Goodier, M., Eggins, E., et al. (2020). Body-worn cameras' effects on police officers and citizen behavior: A systematic review. Campbell Systematic Reviews, 16(3), e1112. https://doi.org/10.1002/cl2.1112.

Maskaly, J., Donner, C., Jennings, W. G., Ariel, B., \& Sutherland, A. (2017). The effects of body-worn cameras (BWCs) on police and citizen outcomes: A state-of-the-art review. Policing: An International Journal of Police Strategies \& Management, 40, 672-688. https://doi.org/10.1108/PIJPSM-03-20170032 .

Mateescu, A., Rosenblat, A., \& boyd, d. (2016). Dreams of accountability, guaranteed surveillance: The promises and costs of body-worn cameras. Surveillance and Society, 14(1), 122-127.

Merola, L. M., Lum, C., Koper, C. S., \& Scherer, A. (2016). Body worn cameras and the courts: A national survey of state prosecutors. Report for the Laura and John Arnold Foundation. Fairfax, VA: Center for Evidence-Based Crime Policy, George Mason University.

Morrow, W. J., Katz, C. M., \& Choate, D. E. (2016). Assessing the impact of police body-worn cameras on arresting, prosecuting, and convicting suspects of intimate partner violence. Police Quarterly, 19(3), 303325. https://doi.org/10.1177/1098611116652850.

Owens, C., Mann, D., \& Mckenna, R. (2014). The Essex body worn video trial: The impact of body worn video on criminal justice outcomes of domestic abuse incidents. Ryton-on-Dunsmore, Coventry, England: College of Policing. Retrieved from bwvsg.com/wp-content/uploads/2013/07/BWV_ReportEssTrial.pdf 
Raudenbush, S., \& Bryk, A. (2002). Hierarchical linear models: Applications and data analysis methods (2nd ed.). Thousand Oaks, CA: Sage.

Rosenbaum, P. R. (2007). Interference between units in randomized experiments. Journal of the American Statistical Association, 102(477), 191-200. https://doi.org/10.1198/016214506000001112.

Smith, M. (2019). Policing: What changed (and didn't) since Michael Brown died? The New York Times. Retrieved from https://www.nytimes.com/2019/08/07/us/racism-ferguson.html

Snijders T. A. B., Bosker R. (2012). Multilevel analysis. Thousand Oaks, CA: Sage.

Spohn, C., DeLone, M., \& Spears, J. (1998). Race/ethnicity, gender and sentence severity in Dade County, Florida: An examination of the decision to withhold adjudication. Journal of Crime and Justice, 21(2), 111-138. https://doi.org/10.1080/0735648X.1998.9721603.

Taylor, E. (2016). Lights, camera, redaction... police body-worn cameras; autonomy, discretion and accountability. Surveillance and Society, 14(1), 128-132.

Todak, N., Gaub, J. E., \& White, M. D. (2018). The importance of external stakeholders for police body-worn camera diffusion. Policing, 41(4), 448-464. https://doi.org/10.1108/PIJPSM-08-2017-0091.

Tseloni, A., \& Pease, K. (2003). Repeat personal victimization. 'Boosts' or 'flags'? The British Journal of Criminology, 43(1), 196-212. https://doi.org/10.1093/bjc/43.1.196.

United States Census Bureau (2021a). City and town population totals: 2010-2019. [Table]. Retrieved from https://www.census.gov/data/tables/time-series/demo/popest/2010s-total-cities-and-towns.html

United States Census Bureau (2021b). Quickfacts - Miami Beach city, Florida [Table]. Retrieved from https:// www.census.gov/quickfacts/fact/table/miamibeachcityflorida/POP010210

Weisburd, D. (2003). Ethical practice and evaluation of interventions in crime and justice: The moral imperative for randomized trials. Evaluation Review, 27(3), 336-354. https://doi.org/10.1177/ 0193841 X03027003007.

Westera, N. J., \& Powell, M. B. (2017). Prosecutors' perceptions of how to improve the quality of evidence in domestic violence cases. Policing and Society, 27(2), 157-172. https://doi.org/10.1080/10439463.2015. 1039002.

White, M. D. (2014). Police body-worn cameras: Assessing the evidence, .

White, M. D., \& Malm, A. (2020). Cops, cameras, and crisis: The potential and the perils of police bodyworn cameras. NYU Press.

White, M. D., Gaub, J. E., Malm, A., \& Padilla, K. E. (2019). Implicate or exonerate? The impact of police body-worn cameras on the adjudication of drug and alcohol cases. Policing: A Journal of Policy and Practice. https://doi.org/10.1093/police/paz043

Williams, M., Weil, N., Rasich, E., Ludwig, J., Chang, H., \& Egrari, S. (2021). Body-Worn Cameras in Policing: Benefits and Costs. NBER Working Paper No. w28622, Available at SSRN: https://ssrn.com/ abstract=3814611

Wilson, D. B. (2021). The relative incident rate ratio effect size for count-based impact evaluations: When an odds ratio is not an odds ratio. Journal of Quantitative Criminology. https://doi.org/10.1007/s10940-02109494-w.

Yokum, D., Ravishankar, A., \& Coppock, A. (2017). Evaluating the effects of police body-worn cameras: A randomized controlled trial. The Lab @ DC. Retrieved from bwc.thelab.dc.gov/TheLabDC_MPD_ BWC_Working_Paper_10.20.17.pdf.

Publisher's note Springer Nature remains neutral with regard to jurisdictional claims in published maps and institutional affiliations.

Kevin Petersen is a doctoral student in the Department of Criminology, Law and Society at George Mason University and a graduate research assistant in the Center for Evidence-Based Crime Policy. His research interests include policing, crime and place, evidence-based crime interventions, guilty pleas, and legal decision-making.

Alejandro Mouro (BA) has worked in law enforcement for the past 15 years. During this time he has worked as a Patrol Officer, a Traffic Homicide Investigator, a Project Manager, and is currently working in the Technical Operations Unit. 
Donald Papy (JD) is an adjunct professor at the University of Miami Law School. Formerly the Chief Deputy City Attorney for the City of Miami Beach and currently consults in private practice on civil rights and employment matters.

Noel Castillo $(\mathrm{PhD})$ has worked in the law enforcement/correctional field for the past 26 years. Noel has received awards for his work as a Hostage Negotiator, Training Officer and for the implementation of community outreach programs. He has a $\mathrm{PhD}$ in Criminal Justice from Nova Southeastern University.

Barak Ariel is a Reader in Experimental Criminology at the Institute of Criminology, University of Cambridge, and an Associate Professor at the Institute of Criminology, Faculty of Law, The Hebrew University of Jerusalem. Barak is presently the Chair of the Division of Experimental Criminology of the American Society of Criminology. 